jungen Schwäne kaum schüdlich sein darfte, mithin auch nicht zur Ausmerzung der damit behafteten Stücke führe. Herr Herm. Bola u hat auf dem Alsterbassin in Hamburg einen ,jugendweissen" Schwan beobachtet, dessen Junges ebenfalls weiss war. Er beabsichtigt mit diesen Schwänen in abgesperrtem Raume Beobachtungen über ihre Nachkommenschaft anzustellen.

\title{
O. Foinroth.
}

\section{Bericht tiber die Januarsitzung 1900.}

Verhandelt Berlin, Montag den 8. Januar 1900, Abends 8 Uhr im Architekten-Vereinshause, Wilhelmstr. 92. II.

Anwesend die Herren: Reichenow, Schalow, Heinroth, Pascal, Thiele, Freese, Haase, Jacobi, R. Rörig, Grunack, Deditius.

Als Gäste: die Herren Hellmayr und Möschler.

Vorsitzender: Herr Schalow. Schriftf: Herr Heinroth.

Nachdem der Vorsitzende die Anwesenden im neuen Jahre begrüsst hat, bemerkt Herr Reichenow zum Protokoll der vorigen Sitzung, dass weisse Dunenjunge bei den auf den Havelseen lebenden Höckerschwänen nicht beobachtet seien. Herr Schalow ehrt darauf das Andenken an den kürzlich verstorbenen verdienten Oologen Geh. Reg. Rat v. Nathusius. Die neu eingegangenen ornithologischen Schriften werden hierauf von den Herren Reichenow und Schalow vorgelegt und besprochen.

Herr Heinroth beschreibt ein Paar seit einiger Zeit im Berliner Zoologischen Garten lebender, der Poëphila acuticauda Gould ähnlicher Vögel als neue Art: Pö̈phila hecki Hnrth. Die Stücke zeigen dasselbe Zeichnungsmuster wie die $P$. acuticauda Gould, nur sind alle Farben bedeutend dunkler, und der Schnabel nicht gelblich, sondern korallrot. $\mathrm{Da}$ beide Arten in Europa wiederholt gezüchtet sind und sich als völlig konstant erwiesen haben, hält der Vortragende die Absonderung der P. hecki Hnrth. für gerechtfertigt. (S. Ornithol. Monatsber. S. 22-23.)

Weiter bespricht Herr Heinroth die Fusshaltung von verschiedenen Möven (Larus canus L., Rissa tridactyla (L.) und Larus ridibundus L.) sowie von der Kampfschnepfe (Totanus pugnax (L.)) bei Frostwetter. Sowohl im Freien wie in dem grossen Flugkäfig des Berliner Zoologischen Gartens hat er beobachtet, dass bei Kälte von genannten Vögeln die Beine nicht wie gewöhnlich nach hinten ausgestreckt, sondern angezogen und 
vollkommen unter das Gefieder der Unterseite versteckt werden. Der Inhalt des Vortrages erscheint in der Märznummer der Ornitholog. Monatsberichte.

Herr Schalow verbreitet sich darauf in Hinblick auf die Einverleibung des Falkenbussards (Buteo zimmermannae Ehmcke) unter die Vögel Deutschlands in der neuen Ausgabe des „Naumann" über die Nomenklatur und Artbeständigkeit dieses Vogels und die Bussardfrage im allgemeinen. Buteo buteo (L.) geht östlich nur bis Ostpreussen, B. vulpinus Licht. schliesst sich im Osten an ihn an, sodass man für das Verbreitungsgebiet des $B$. aimmermannae entweder einen schmalen Streifen zwischen diesen beiden Arten annehmen muss, oder aber $B$. zimmermannae mit $B$. vulpinus zusammenfällt. Bei der starken Veränderlichkeit der Bussarde in Grösse und Form darf aus wenigen Stücken überhaupt kein Schluss gezogen werden. Der Vortragende bespricht die Ansichten verschiedener Autoren und kommt zu dem Schlusse, dass, wenn $B$. zimmermannae mit $B$. vulpinus identisch sein sollte, ersterer Name als der richtige anzusehen sei.

Herr Reichenow spricht sich im Sinne des Vorredners aus, legt verschiedene seltenere Vogelbälge vor und geht auf einen eigentümlichen Webervogel nit ganz verkürzter I. Handschwinge und sehr kurzem Schwanze ein. Seine bereits früher aufgestellte Ansicht, es hier mit einer neuen Gattung zu thun zu haben, ist durch die Übersendung von weiteren 3 Stücken von Hartert bestätigt worden. Brachycope anomala Rchw. nennt der Vortragende die vorliegende Form.

Hr. Reichenow spricht ferner äber einige Abarten von Halcyon semicaeruleus (Forsk.) und kennzeichnet diese folgendermassen:

H. semicaerulea typica: Das Blau auf Bürzel, Schwanz und Schwingen schön kobaltblau. Nordostafrika südwärts bis zum Pangani.

H. s. hyacinthina Rchw. n. subsp.: Das Blau der vorgenannten Teile ins Veilchenfarbene ziehend, prächtig hell hyazinthblau oder smaltblau, mit starkem Porzellanglanz, also wie das Blau bei H. pallidiventris. Sansibar, Useguha.

$H$. s. rufiventris Sw.: Blau auf Bürzel, Schwanz und Schwingen sehr hell, ins Grünliche ziehend, nilblau. Westafrika.

Heinroth. 